\title{
Hot topic: 16S rRNA gene sequencing reveals the microbiome of the virgin and pregnant bovine uterus
}

\author{
S. G. Moore, ${ }^{*}$ A. C. Ericsson, $\ddagger$ S. E. Poock,§ P. Melendez,§ and M. C. Lucy ${ }^{\star 1}$ \\ *Division of Animal Sciences, and \\ †Department of Veterinary Pathobiology, University of Missouri, Columbia 65211 \\ łUniversity of Missouri Metagenomics Center, University of Missouri, Columbia 65201 \\ $\S$ College of Veterinary Medicine, University of Missouri, Columbia 65211
}

\section{ABSTRACT}

We tested the hypothesis that the uterus of virgin heifers and pregnant cows possessed a resident microbiome by $16 \mathrm{~S}$ rRNA gene sequencing of the virgin and pregnant bovine uterus. The endometrium of 10 virgin heifers in estrus and the amniotic fluid, placentome, intercotyledonary placenta, cervical lumen, and external cervix surface (control) of 5 pregnant cows were sampled using aseptic techniques. The DNA was extracted, the V4 hypervariable region of the 16S rRNA gene was amplified, and amplicons were sequenced using Illumina MiSeq technology (Illumina Inc., San Diego, CA). Operational taxonomic units (OTU) were generated from the sequences using Qiime v1.8 software, and taxonomy was assigned using the Greengenes database. The effect of tissue on the microbial composition within the pregnant uterus was tested using univariate (mixed model) and multivariate (permutational multivariate ANOVA) procedures. Amplicons of 16S rRNA gene were generated in all samples, supporting the contention that the uterus of virgin heifers and pregnant cows contained a microbiome. On average, 53, 199, 380, 382, 525, and 13,589 reads annotated as $16,35,43,63,48$, and 176 OTU in the placentome, virgin endometrium, amniotic fluid, cervical lumen, intercotyledonary placenta, and external surface of the cervix, respectively, were generated. The 3 most abundant phyla in the uterus of the virgin heifers and pregnant cows were Firmicutes, Bacteroidetes, and Proteobacteria, and they accounted for approximately 40,35 , and $10 \%$ of the sequences, respectively. Phyla abundance was similar between the tissues of the pregnant uterus. Principal component analysis, one-way PERMANOVA analysis of the BrayCurtis similarity index, and mixed model analysis of the Shannon diversity index and Chao1 index demonstrated that the microbiome of the control tissue (external

Received January 13, 2017.

Accepted March 12, 2017.

${ }^{1}$ Corresponding author: lucym@missouri.edu surface of the cervix) was significantly different from that of the amniotic fluid, intercotyledonary placenta, and placentome tissues. Interestingly, many bacterial species associated with postpartum uterine disease (i.e., Trueperella spp., Acinetobacter spp., Fusobacteria spp., Proteus spp., Prevotella spp., and Peptostreptococcus spp.) were also present in the uterus of virgin heifers and of pregnant cows. The presence of $16 \mathrm{~S}$ rRNA gene sequence reads in the samples from the current study suggests that the uterine microbiome is established by the time a female reaches reproductive maturity, and that pregnancies are established and maintained in the presence of a uterine microbiome.

Key words: microbiome, uterine health, uterus, pregnancy

\section{Hot Topic}

Pathogenic bacteria are ubiquitous in the postpartum uterus of cattle. Some cows develop puerperal (acute) metritis, which is clinically diagnosed by fever, loss of appetite, fetid discharge, and inflammation of the uterus. Other cows develop metritis (fetid discharge without fever or loss of appetite) or subclinical endometritis (superficial inflammation of the endometrium). One-half to two-thirds of cows remain healthy (no uterine disease; Sheldon et al., 2009). Cows that develop uterine disease have reduced feed intake and milk production and are less likely to become pregnant (Huzzey et al., 2007; Giuliodori et al., 2013). Escherichia coli, Trueperella pyogenes, Prevotella spp., Fusobacterium necrophorum, Bacteroidetes spp., and Firmicutes spp. are the predominant taxa associated with uterine disease postpartum. These bacteria, however, have also been identified in the uterus of healthy cows (Santos et al., 2011; Jeon et al., 2015; Knudsen et al., 2015). The fact that diseased as well as healthy cows harbor some of the same microbes indicates that uterine disease is more likely dependent on the overgrowth of specific bacteria and the responsiveness of the immune system. This overgrowth of some specific bacterium 
may reduce overall bacterial diversity, a feature that is commonly associated with uterine disease (Jeon et al., 2015; Knudsen et al., 2015; Carneiro et al., 2016).

The DNA sequencing of $16 \mathrm{~S}$ rRNA gene amplicon libraries has greatly advanced our knowledge of bacterial communities (termed the "microbiome") and has identified bacteria previously not known to exist because they failed to grow when cultured in vitro. Traditional sites for the microbiome were the intestine, oral cavity, respiratory tract, skin, and reproductive tract (primarily the vagina and cervix; Althani et al., 2016). A sterile uterus, however, was traditionally thought to be a prerequisite for a healthy pregnancy (Wassenaar and Panigrahi, 2014). Yet, bacteria have been detected in the placenta of women with healthy pregnancies (Steel et al., 2005; Stout et al., 2013; Aagaard et al., 2014), and specific microbes of the endometrium are supportive of pregnancy outcome in women undergoing embryo transfer (Moreno et al., 2016).

The predominant bacteria in metritic cows are found in the environment and are believed to gain access to the uterus from the environment when the cow calves (Bromfield et al., 2015). The same bacteria that cause metritis, however, are part of the normal bovine microbiome and they are nonpathogenic when found outside of the uterus. In addition to those coming from the environment, metritis-causing bacteria might also enter via a hematogenous route. This raises the possibility of a microbiome resident in the uterus. If true, then the cow must be able to hold the microbial population in check during pregnancy to prevent an infection that would, in all likelihood, result in abortion. In the current study, the primary hypothesis was to test for the presence of bacteria in the uterus of virgin heifers and pregnant cows, with the secondary hypothesis being that the microbiome of the pregnant uterus was tissue-specific. The 16S rRNA gene sequences detected in the samples from the current study supported our primary hypothesis; however, only minor differences in microbiome were detected between tissues within the pregnant uterus.

Reproductive tract samples from virgin heifers and pregnant cows were the focus of the current study. Ten virgin heifers (14 mo of age, and of Holstein and Jersey admixture) reared at the University of Missouri Southwest Research Center (Mt. Vernon, MO) were enrolled on a 14-d CIDR-PGF ${ }_{2 \alpha}$ synchronization protocol for timed AI as described by Abel et al. (2017). Each heifer received a controlled internal drug release (CIDR) insert containing $1.38 \mathrm{~g}$ of progesterone (Zoetis, New York, NY) per vaginum from d 0 to 14; an i.m. injection of $\mathrm{PGF}_{2 \alpha}$ containing $25 \mathrm{mg}$ of dinoprost tromethamine (Lutalyse; Zoetis) on d 30; and an i.m. injection of gonadotropin-releasing hormone containing
$100 \mathrm{mg}$ of gonadorelin hydrochloride (Factrel; Zoetis) $72 \mathrm{~h}$ later, coinciding with AI. Endometrial biopsies were collected on d 16 ( 2 d after CIDR removal) when the heifers were displaying estrus. The vulva and perineal area were sanitized with an antimicrobial solution ( $2 \%$ chlorhexidine gluconate; VetOne, Boise, ID) and dried with a paper towel. A standard stainless steel AI gun was fitted with a plastic AI sheath, and a plastic coverall (Continental Plastic Corp., Delavan, WI) was used to cover both the AI sheath and gun. The AI gun with sheath and coverall were placed into the vagina and the tip of the gun was positioned at the cervical os. The coverall was pierced by forcing the sheath through. The sheath was manipulated through the cervix into the uterine body. The endometrium biopsy tool (Wolf 8380.01; Richard Wolf GmbH, Knittlingen, Germany) was guided through the sheath. Endometrial biopsies (5 $\times 1 \mathrm{~mm}$ ) were collected from 4 sites in the uterine horn ipsilateral to the preovulatory follicle. Three endometrium samples were placed in one sterile tube, snap frozen in liquid nitrogen, and stored at $-80^{\circ} \mathrm{C}$ until DNA extraction. The fourth endometrium sample was fixed in $10 \%$ buffered formalin. Biopsy tools were cleaned, washed in antimicrobial solution (1:10 2\% chlorhexidine gluconate), and rinsed with sterile filtered PBS before each biopsy.

Tissue was also collected from reproductive tracts of pregnant Holstein cows processed at a slaughter facility in Green Bay, Wisconsin. Reproductive tracts were examined following evisceration and 5 third-trimester pregnant tracts were selected. Samples of placentome (both caruncular and cotyledonary tissue), intercotyledonary placenta, amniotic fluid, and cervical lumen were collected using aseptic techniques. A fifth tissue sample from the outside of the cervix (exposed to the environment within the slaughter facility) was collected as a positive control. Individually wrapped surgical tools that had been previously washed with soap, rinsed with filter-sterilized water, and sterilized by autoclaving were used for sample collection. Amniotic fluid (10 mL) was aspirated into a sterile syringe using a disposable hypodermic needle $(18$-gauge $\times 38.1 \mathrm{~mm})$. All samples were placed in individual sterile tubes, snap frozen in liquid nitrogen, and stored at $-80^{\circ} \mathrm{C}$ until DNA extraction. After sample collection, the fetal crown-rump length was measured to estimate fetal age. The sex and predicted age of fetuses $1,2,3,4$, and 5 were female and $187 \mathrm{~d}$, female and $249 \mathrm{~d}$, female and $216 \mathrm{~d}$, male and $200 \mathrm{~d}$, and female and $224 \mathrm{~d}$, respectively.

DNA was extracted using a manual precipitation protocol as previously described (Hart et al., 2015). The University of Missouri DNA Core facility performed library construction and sequencing. Concentrations of DNA were determined via fluorometry (Qubit ds- 
DNA BR assay, Life Technologies, Carlsbad, CA) and samples were stored at $-20^{\circ} \mathrm{C}$. All samples yielding greater than $100 \mathrm{ng}$ of total DNA were normalized to $3.51 \mathrm{ng} / \mu \mathrm{L}$ for PCR amplification. Bacterial 16S rRNA amplicons were generated via amplification of the V4 hypervariable region of the $16 \mathrm{~S}$ rRNA gene using single-indexed universal primers (U515F/806R) flanked by Illumina standard adapter sequences (Illumina Inc., San Diego, CA) and the following parameters: $98^{\circ} \mathrm{C}$ $(3: 00)+\left[98^{\circ} \mathrm{C}(0: 15)+50^{\circ} \mathrm{C}(0: 30)+72^{\circ} \mathrm{C}(0: 30)\right] \times$ 25 cycles $+72^{\circ} \mathrm{C}(7: 00 ;$ min:s). The $\mathrm{V} 4$ region of the $16 \mathrm{~S}$ rRNA gene was selected for library generation because this region yields optimal community clustering (Caporaso et al., 2011). Amplicons were then pooled for sequencing using the Illumina MiSeq platform and V2 chemistry with $2 \times 250$-bp paired-end reads, as previously described (Ericsson et al., 2015). Informatics processing assembly, binning, and annotation of DNA sequences was performed at the University of Missouri Informatics Research Core Facility. Briefly, contiguous DNA sequences were assembled using FLASH software (Magoč and Salzberg, 2011), and culled if found to be short after trimming for a base quality less than 31 . Qiime v1.8 software (Kuczynski et al., 2011) was used to perform de novo and reference-based chimera detection and removal, and remaining contiguous sequences were assigned to operational taxonomic units (OTU) via de novo OTU clustering and a criterion of $97 \%$ nucleotide identity. Taxonomy was assigned to selected OTU using BLAST (Altschul et al., 1997) against the Greengenes database (http://greengenes.lbl.gov/cgibin/nph-index.cgi; DeSantis et al., 2006) of 16S rRNA gene sequences and taxonomy. Qiime also generated a table with the relative abundance of each taxa in each sample for comparative analysis between tissues. Multivariate analysis of 1/4-root transformed relative abundance data was implemented in PAST version 3.14 (Hammer et al., 2001). Permutational multivariate ANOVA (PERMANOVA) was used to test for effects of tissue on microbial composition, using the Bray-Curtis similarity index, a measure of compositional similarity of the tissues based on OTU abundance. A mixed model (PROC MIXED) was fitted in SAS 9.3 (SAS Institute Inc., Cary, NC) with tissue as the fixed effect and cow nested within tissue as the random effect to test whether the microbiome within the pregnant uterus was tissue-specific. Effects were deemed significant at $P<0.05$.

To our knowledge, this study is the first to report on the presence of a microbiome in the uterus of pregnant dairy cows. A microbiome was also detected in the uterus of the virgin heifers, in agreement with a previous report (Fischer-Tenhagen et al., 2012) that used in vitro culture methods. $16 \mathrm{~S}$ rRNA gene sequences were detected in all tissues tested (Table 1). On average, 53, $199,380,382,525$, and 13,589 reads were annotated as $16,35,43,63,48$, and 176 OTU in the placentome, virgin endometrium, amniotic fluid, cervical lumen, intercotyledonary placenta, and control tissues, respectively. Three hundred and thirty-three OTU were present across all samples, of which 60, 153, 78, 27, 12, and 3 were classified to the species, genus, family, order, class, and phylum levels, respectively (Supplementary Table S1; https://doi.org/10.3168/jds.2017-12592). To put these values in context, $16 \mathrm{~S}$ rRNA gene sequencing has generated $1,362,83,000$, and 47,758 sequence reads on average from uterine fluid and uterine swabs of the postpartum cows and from the rumen of dairy cows, respectively (Santos and Bicalho, 2012; Jeon et al., 2015; Mao et al., 2015). The 3 most abundant phyla in the uterus of the virgin heifers were Firmicutes, Bacteroidetes, and Proteobacteria and they accounted for 40, 36 , and $10 \%$ of the sequences. The low number of reads in the endometrium of the virgin heifers and in the reproductive tract of pregnant cows is consistent with previous studies of the microbiome in the endometrium and placenta of women (Aagaard et al., 2014; Moreno et al., 2016). The presence of bacterial 16S rRNA gene sequences in the virgin heifer uterus supports the in vitro culture data of Fischer-Tenhagen et al. (2012) and suggests that a uterine microbiome is established by the time a female reaches reproductive maturity.

The 3 most abundant phyla of the pregnant uterus were Firmicutes, Bacteroidetes, and Proteobacteria and they accounted for 35 to $42 \%, 23$ to $33 \%$, and 2 to $15 \%$ of the reads; their abundance was similar $(P>$ 0.10 ) between the tissues tested (Supplementary Figure S1; https://doi.org/10.3168/jds.2017-12592). Principal component analysis illustrated that the microbiomes of the amniotic fluid, intercotyledonary placenta, placentome, and cervical lumen were similar to each other but distinct from the control tissue (Figure 1A). One-way PERMANOVA analysis of the Bray-Curtis similarity index detected a significant effect of tissue $(P<0.0001)$, with the control significantly different from the amniotic fluid $(P<0.01)$, cervical lumen $(P<0.01)$, intercotyledonary placenta $(P<0.008)$, and placentome $(P$ $<0.008$ ). Mixed-model analysis of the $\alpha$-diversity measures (Chao1 index and Shannon diversity index; Figure $1 \mathrm{~B}$ and $\mathrm{C}$ ) indicated significant differences between the control and amniotic fluid (Chao1, $P<0.0009$; Shannon, $P<0.004$ ), placentome (Chao1, $P<0.0001$; Shannon, $P<0.0001)$, and intercotyledonary placenta (Chao1, $P<0.006$; Shannon, $P<0.02$ ), and between the placentome and cervical lumen (Chao1, $P<0.007$; Shannon, $P<0.004)$. Forty-one OTU were common to each tissue tested and they accounted for $76.80 \%$ of the OTU. Nine, 2, 89, 6, and 1 OTU were unique to the 


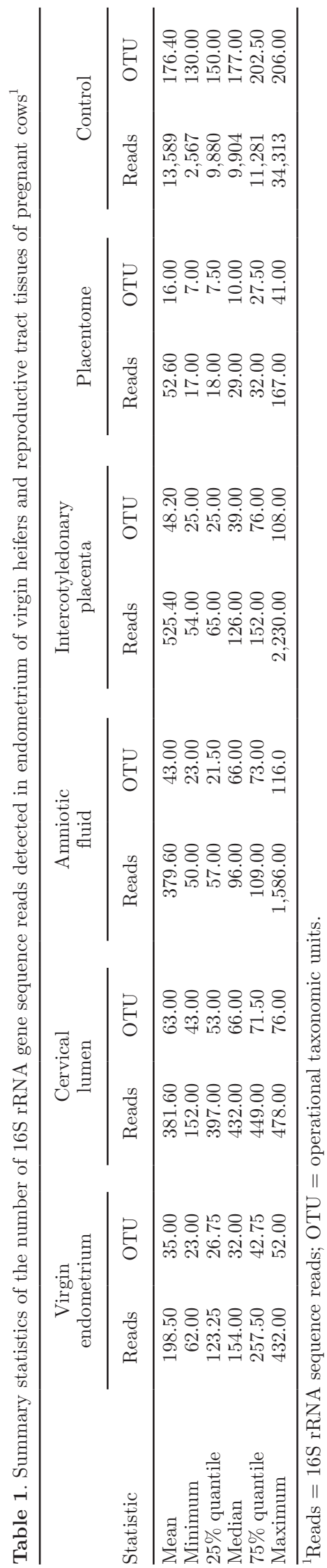

amniotic fluid, placentome, control, cervical lumen, and intercotyledonary placenta tissues, respectively, and, on average, accounted for $5.50,1.49,1.27,1.13$, and $0.02 \%$ of the OTU (Supplementary Table S2; https://doi. org/10.3168/jds.2017-12592). Overall, these analyses suggest only minor differences in the microbiome present in each tissue of the pregnant bovine uterus.

Sequencing and analysis of the 16S rRNA gene is a powerful technique for characterizing low-abundance microbial populations that are not amenable to in vitro culture. There are, however, caveats to the data that we present. First, we do not know if the taxa identified were viable at the time of sample collection. The $16 \mathrm{~S}$ rRNA gene sequences that we detected could be from nonviable remnants of an earlier bacterial infection. This concern is shared by all microbiome studies that use $16 \mathrm{~S}$ rRNA gene sequencing. Second, some of the 16S rRNA gene sequences may have originated from environmental contamination of the sample introduced by the atmosphere or from the sample collection tools, or by the CIDR used to synchronize the estrous cycle of the heifers (Padula and Macmillan, 2006). We believe that the procedures used in the current study were sufficient to minimize environmental contamination, although sampling of the virgin heifer uterus following hysterectomy or slaughter would further have reduced the risk. Sterile and single-use needles, syringes, scalpels, and sample tubes were used for sample collection. Samples were immediately snap frozen in liquid nitrogen to preserve the microbial profile. We detected a greater number of $16 \mathrm{~S}$ rRNA gene sequences in the control tissue samples of external cervix than in the internal uterine samples. The control tissues also differed from all others with respect to the composition of the microbiome that we detected (Figure 2). This result provided evidence to support our contention that the internal uterine samples of the pregnant cows and virgin heifers were not extensively contaminated by the environmental microbiome at the time of sample collection. The current findings might also reflect contamination of the sample collection tools or the reagents used in the DNA extraction process or in the PCR and sequencing pipeline. Although no negative controls were processed in parallel to the samples in this study, the University of Missouri Metagenomics Center does routinely process such samples. Historically, such samples have either failed to generate any high-quality reads or they have returned extremely low read counts (i.e., typically fewer than 100 reads). While it could be argued that some of the data generated from some of the placental samples might represent contaminating DNA sequences, all other sample sites resulted in sufficient coverage to make reagent or instrument contamination unlikely. 

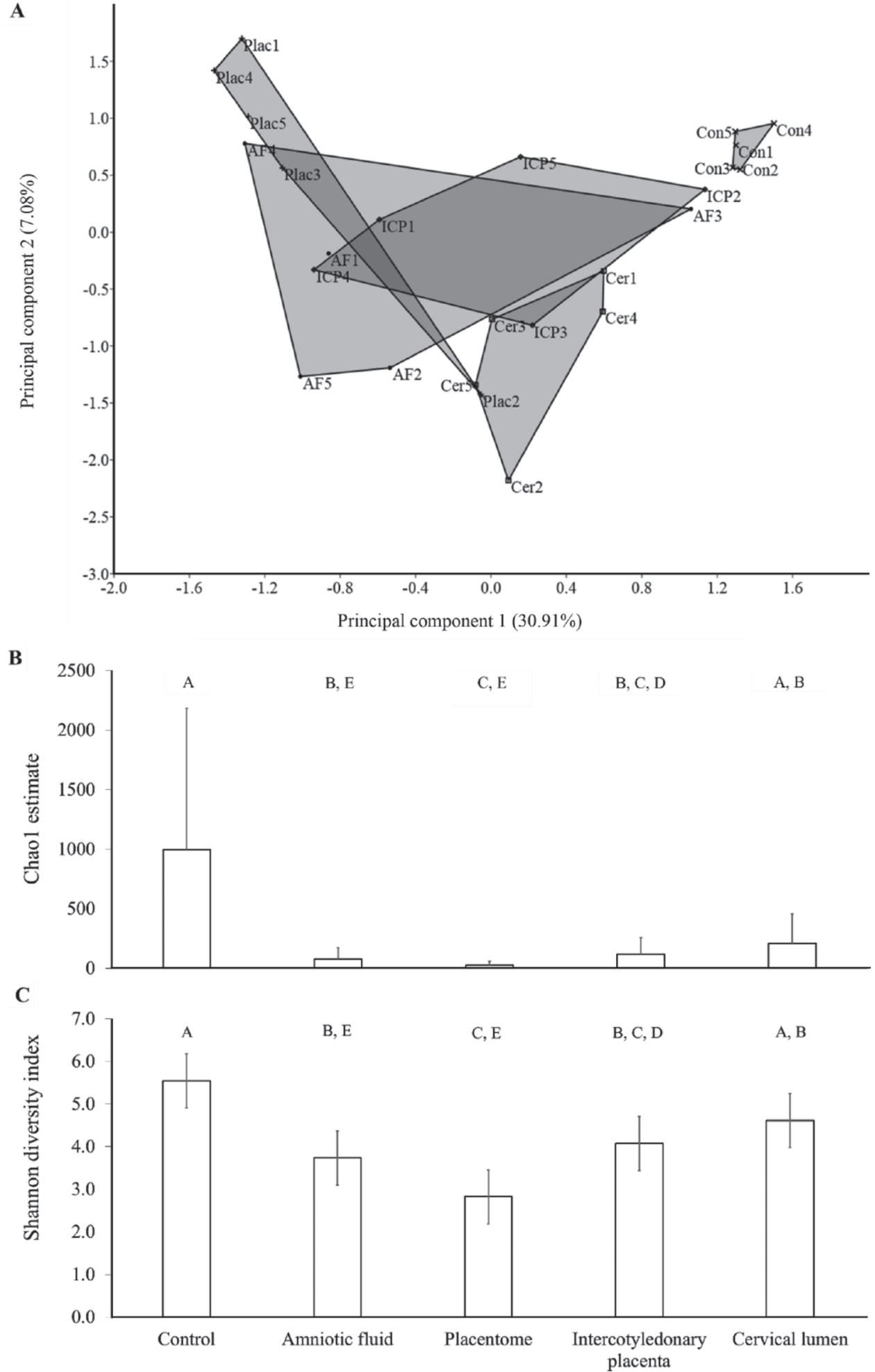

Figure 1. The effect of tissue on the microbiome of the pregnant bovine reproductive tract. Principal component analysis (A) and comparison of the Chao1 (B) and Shannon diversity (C) indices between the microbiome of the reproductive tracts in 5 pregnant cows: external cervix (control; Con1 to Con5), cervical lumen (Cer1 to Cer5), intercotyledonary placenta (ICP1 to ICP5), amniotic fluid (AF1 to AF5), or placentome (Plac1 to Plac5). The mean (95\% CI) Chao1 index values were 996.5 (454.6-2184.0), 77.6 (35.4-170.1), 26.6 (12.1-58.2), 118.5 (54.1-259.7), and 209.6 (95.7-459.5), and the mean (95\% CI) Shannon index values were 5.54 (4.91-6.18), 3.73 (3.10-4.37), 2.82 (2.19-3.46), 4.08 (3.44-4.71), 4.61 (3.98-5.25) for the control, amniotic fluid, placentome, intercotyledonary placenta, and cervical lumen, respectively. Means with different letters (A to E) differ at $P \leq 0.05$. 


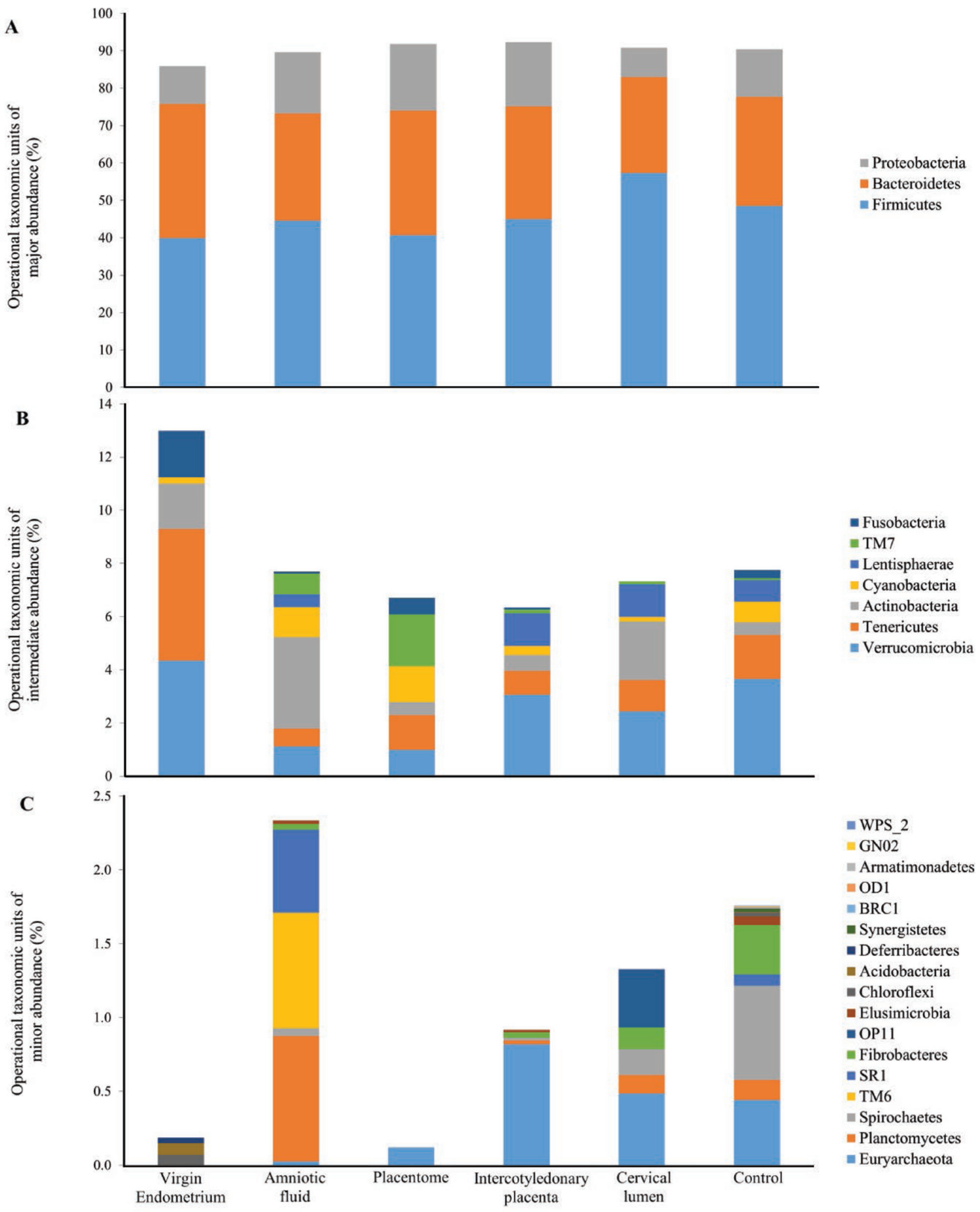

Figure 2. Stacked bar charts illustrating the relative abundance of major (A), intermediate (B), and minor (C) operational taxonomic units classified at the phyla level detected in the endometrium of 10 virgin dairy heifers, and the amniotic fluid, placentome, intercotyledonary placenta, cervical lumen, and external cervix (control) of 5 Holstein dairy cows during the last trimester of pregnancy. Color version available online. 
The detection of $16 \mathrm{~S}$ rRNA gene sequences in the uterus of virgin heifers and pregnant cows challenges the dogma that a sterile uterus is required for the establishment and maintenance of pregnancy. It also raises questions of how the microbiome is established in the uterus, how and why a microbiome remains, and how the microbiome influences reproductive biology. In both groups of females, the uterine microbiome most likely occurred by the intrauterine ascension of bacteria from the vagina and cervix (Sisti et al., 2016), as would be likely to occur during the periestrous period and at breeding. Hematogenous transfer of bacteria from the maternal circulation across the placenta offers an alternative but likely complementary mechanism (Fardini et al., 2010; Aagaard et al., 2014). Because bacteria are most likely to only enter the placentome and amnion after the pregnancy has been established, this mechanism seems plausible and is consistent with previous studies that detected bacteria by culture, $16 \mathrm{~S}$ rRNA gene sequencing, or morphological assessment in the placenta and amniotic fluid of women with healthy and compromised pregnancies (Stout et al., 2013; Aagaard et al., 2014). The 10 heifers involved in this study were clinically healthy. Eosinophils and polymorphonuclear neutrophils were detected by a trained investigator ( $\mathrm{T}$. J. Evans, College of Veterinary Medicine, University of Missouri) and, as would be expected, indicated some level of inflammation in the endometrium of 5 heifers (3 with minor and 2 with moderate level inflammation). No immune cells were identified in the other 5 heifers. Of the 3 heifers that did not become pregnant when they were inseminated $17 \mathrm{~d}$ later, 1 heifer had no inflammation, 1 had minor inflammation, and 1 had moderate inflammation, respectively, in the endometrium. Examination of the principal component plot did not identify any separation between the samples based on the presence or absence of inflammation. Although the reasons for slaughter of the 5 pregnant cows is unknown, each reproductive tract and fetus appeared normal upon postmortem examination.

Considering that the postpartum uterus is associated with a high abundance of 16s rRNA gene sequence reads, the relevance of the low number of reads in the uterus of the virgin heifer and pregnant cow to subsequent uterine health merits challenge. In contrast to the current dogma that regards the pregnant uterus as sterile until contamination with the environmental microbiome at calving, we believe that the uterus possesses a resident microbiome. We propose that the microbiome is maintained in a quiescent state in the virgin or pregnant uterus until the periparturient period, at which time the mechanisms holding the microbiome in check are removed. Changes in the uterine biology associated with parturition, therefore, lead to proliferation of a postpartum uterine microbiome that is, at least partially, already resident inside the uterus. That Trueperella spp., Acinetobacter spp., Fusobacteria spp., Proteus spp., Bacteroidetes including Prevotella spp., and Firmicutes, including Peptostreptococcus spp., are bacteria associated with postpartum uterine disease (Carneiro et al., 2016) and were present in the uterus of many of the virgin heifers and pregnant cows supports this hypothesis.

\section{ACKNOWLEDGMENTS}

The authors express their gratitude to American Foods Group LLC (Green Bay, WI) for facilitating access to the slaughter facility. Funding for the study was received from USDA Animal Health Formula Funds and the Food for the 21st Century Program (University of Missouri).

\section{REFERENCES}

Aagaard, K., J. Ma, K. M. Antony, R. Ganu, J. Petrosino, and J. Versalovic. 2014. The placenta harbors a unique microbiome. Sci. Transl. Med. 6:237ra65 https://doi.org/10.1126/ scitranslmed.3008599.

Abel, J. M., B. E. Bishop, J. M. Thomas, M. R. Ellersieck, S. E. Poock, M. F. Smith, and D. J. Patterson. 2017. Comparing strategies to synchronize estrus before fixed-time artificial insemination in primiparous 2-year-old beef cows. Theriogenology 87:306-315. https://doi.org/10.1016/j.theriogenology.2016.09.010.

Althani, A. A., H. E. Marei, W. S. Hamdi, G. K. Nasrallah, M. E. El Zowalaty, S. Al Khodor, M. Al-Asmakh, H. Abdel-Aziz, and C. Cenciarelli. 2016. Human microbiome and its association with health and diseases: Human microbiome diseases. J. Cell. Physiol. 231:1688-1694. https://doi.org/10.1002/jcp.25284.

Altschul, S. F., T. L. Madden, A. A. Schäffer, J. Zhang, Z. Zhang, W. Miller, and D. J. Lipman. 1997. Gapped BLAST and PSI-BLAST: A new generation of protein database search programs. Nucleic Acids Res. 25:3389-3402.

Bromfield, J. J., J. E. Santos, J. Block, R. S. Williams, and I. M. Sheldon. 2015. Physiology and Endocrinology Symposium: Uterine infection: Linking infection and innate immunity with infertility in the high-producing dairy cow. J. Anim. Sci. 93:2021-2033.

Caporaso, J. G., C. L. Lauber, W. A. Walters, D. Berg-Lyons, C. A. Lozupone, P. J. Turnbaugh, N. Fierer, and R. Knight. 2011. Global patterns of $16 \mathrm{~S}$ rRNA diversity at a depth of millions of sequences per sample. Proc. Natl. Acad. Sci. USA 108:4516-4522. https://doi.org/10.1073/pnas.1000080107.

Carneiro, L. C., J. G. Cronin, and I. M. Sheldon. 2016. Mechanisms linking bacterial infections of the bovine endometrium to disease and infertility. Reprod. Biol. 16:1-7. https://doi.org/10.1016/j. repbio.2015.12.002.

DeSantis, T. Z., P. Hugenholtz, N. Larsen, M. Rojas, E. L. Brodie, K. Keller, T. Huber, D. Dalevi, P. Hu, and G. L. Andersen. 2006. Greengenes, a chimera-checked 16S rRNA gene database and workbench compatible with ARB. Appl. Environ. Microbiol. 72:5069-5072.

Ericsson, A. C., J. W. Davis, W. Spollen, N. Bivens, S. Givan, C. E. Hagan, M. McIntosh, and C. L. Franklin. 2015. Effects of vendor and genetic background on the composition of the fecal microbiota of inbred mice. PLoS One 10:e0116704 https://doi.org/10.1371/ journal.pone.0116704.

Fardini, Y., P. Chung, R. Dumm, N. Joshi, and Y. W. Han. 2010 Transmission of diverse oral bacteria to murine placenta: Evidence for the oral microbiome as a potential source of intrauterine in- 
fection. Infect. Immun. 78:1789-1796. https://doi.org/10.1128/ IAI.01395-09.

Fischer-Tenhagen, C., X. von Krueger, and W. Heuwieser. 2012. Short communication: Evaluation of vaginal discharge following treatment with a progesterone insert. J. Dairy Sci. 95:4447-4451. https://doi.org/10.3168/jds.2011-5224.

Giuliodori, M. J., R. P. Magnasco, D. Becu-Villalobos, I. M. LacauMengido, C. A. Risco, and R. L. de la Sota. 2013. Metritis in dairy cows: Risk factors and reproductive performance. J. Dairy Sci. 96:3621-3631. https://doi.org/10.3168/jds.2012-5922.

Hammer, Ø., D. A. T. Harper, and P. D. Ryan. 2001. PAST: Paleontological Statistics Software Package for Education and Data Analysis. Palaeontologia Electronica 4(1). https://folk.uio.no/ ohammer/past/.

Hart, M. L., A. Meyer, P. J. Johnson, and A. C. Ericsson. 2015. Comparative evaluation of DNA extraction methods from feces of multiple host species for downstream next-generation sequencing. PLoS One 10:e0143334.

Huzzey, J. M., D. M. Veira, D. M. Weary, and M. A. G. von Keyserlingk. 2007. Prepartum behavior and dry matter intake identify dairy cows at risk for metritis. J. Dairy Sci. 90:3220-3233. https:// doi.org/10.3168/jds.2006-807.

Jeon, S. J., A. Vieira-Neto, M. Gobikrushanth, R. Daetz, R. D. Mingoti, A. C. B. Parize, S. L. de Freitas, A. N. L. da Costa, R. C. Bicalho, S. Lima, K. C. Jeong, and K. N. Galvão. 2015. Uterine microbiota progression from calving until establishment of metritis in dairy cows. Appl. Environ. Microbiol. 81:6324-6332. https:// doi.org/10.1128/AEM.01753-15.

Knudsen, L. R. V., C. C. Karstrup, H. G. Pedersen, J. S. Agerholm, T. K. Jensen, and K. Klitgaard. 2015. Revisiting bovine pyometraNew insights into the disease using a culture-independent deep sequencing approach. Vet. Microbiol. 175:319-324. https://doi. org/10.1016/j.vetmic.2014.12.006.

Kuczynski, J., J. Stombaugh, W. A. Walters, A. González, J. G. Caporaso, and R. Knight. 2011. Using QIIME to analyze 16S rRNA gene sequences from microbial communities. A. D. Baxevanis, D. B. Davison, R. D. M. Page, G. A. Petsko, L. D. Stein, and G. D. Stormo, ed. John Wiley \& Sons Inc., Hoboken, NJ.

Magoč, T., and S. L. Salzberg. 2011. FLASH: Fast length adjustment of short reads to improve genome assemblies. Bioinformatics $27: 2957-2963$

Mao, S., M. Zhang, J. Liu, and W. Zhu. 2015. Characterising the bacterial microbiota across the gastrointestinal tracts of dairy cattle:
Membership and potential function. Sci. Rep. 5:16116. https://doi. org $/ 10.1038 /$ srep16116.

Moreno, I., F. M. Codoñer, F. Vilella, D. Valbuena, J. F. MartinezBlanch, J. Jimenez-Almazán, R. Alonso, P. Alamá, J. Remohí, A. Pellicer, D. Ramon, and C. Simon. 2016. Evidence that the endometrial microbiota has an effect on implantation success or failure. Am. J. Obstet. Gynecol. https://doi.org/10.1016/j. ajog.2016.09.075.

Padula, A. M., and K. L. Macmillan. 2006. Effect of treatment with two intravaginal inserts on the uterine and vaginal microflora of early postpartum beef cows. Aust. Vet. J. 84:204-208.

Santos, T. M. A., and R. C. Bicalho. 2012. Diversity and succession of bacterial communities in the uterine fluid of postpartum metritic, endometritic and healthy dairy cows. PLoS One 7:e53048. https:// doi.org/10.1371/journal.pone.0053048.

Santos, T. M. A., R. O. Gilbert, and R. C. Bicalho. 2011. Metagenomic analysis of the uterine bacterial microbiota in healthy and metritic postpartum dairy cows. J. Dairy Sci. 94:291-302. https:// doi.org/10.3168/jds.2010-3668.

Sheldon, I. M., J. Cronin, L. Goetze, G. Donofrio, and H.-J. Schuberth. 2009. Defining postpartum uterine disease and the mechanisms of infection and immunity in the female reproductive tract in cattle. Biol. Reprod. 81:1025-1032. https://doi.org/10.1095/ biolreprod.109.077370.

Sisti, G., T. T. Kanninen, and S. S. Witkin. 2016. Maternal immunity and pregnancy outcome: Focus on preconception and autophagy. Genes Immun. 17:1-7.

Steel, J. H., S. Malatos, N. Kennea, A. D. Edwards, L. Miles, P. Duggan, P. R. Reynolds, R. G. Feldman, and M. H. F. Sullivan. 2005. Bacteria and inflammatory cells in fetal membranes do not always cause preterm labor. Pediatr. Res. 57:404-411. https://doi org/10.1203/01.PDR.0000153869.96337.90

Stout, M. J., B. Conlon, M. Landeau, I. Lee, C. Bower, Q. Zhao, K. A. Roehl, D. M. Nelson, G. A. Macones, and I. U. Mysorekar. 2013. Identification of intracellular bacteria in the basal plate of the human placenta in term and preterm gestations. Am. J. Obstet. Gynecol. 208:226.e1-226.e7. https://doi.org/10.1016/j. ajog.2013.01.018.

Wassenaar, T. M., and P. Panigrahi. 2014. Is a foetus developing in a sterile environment? Lett. Appl. Microbiol. 59:572-579. https:// doi.org/10.1111/lam.12334. 